\title{
INFLUÊNCIA DA PODA NOS DEFEITOS ESTRUTURAIS DE Ficus benjamina NA FLORESTA URBANA DE ITANHAÉM - SÃO PAULO
}

\author{
INFLUENCE OF PRUNING ON THE STRUCTURAL DEFECTS OF Ficus benjamina IN \\ THE URBAN FOREST OF ITANHAÉM -SÃO PAULO
}

\author{
Tamara Ribeiro Botelho de Carvalho Maria ${ }^{1}$, Daniela Biondi² , Alexandre Behling ${ }^{3}$, \\ Nilton Jose de Sousa ${ }^{4}$
}

\begin{abstract}
RESUMO
O conhecimento dos defeitos estruturais que comprometem a qualidade da arborização urbana e o padrão das principais espécies que compõem a floresta urbana é fundamental para o seu manejo e planejamento, podendo evitar e reduzir o risco de queda de árvores. Considerando que a poda é a prática de manejo mais comum na floresta urbana estabelecida, e que as árvores de Ficus benjamina são frequentes nas florestas urbanas em todo o mundo, esta pesquisa teve como objetivo determinar os principais defeitos estruturais que comprometem a saúde e estrutura dessas árvores, encontradas na Floresta Urbana da cidade de Itanhaém-SP, bem como a relação entre os defeitos e a presença de podas. Para isso, as árvores foram avaliadas quanto à frequência e tipo de poda, mensuradas as variáveis dendrométricas e identificada a presença de defeitos. Como resultado, a poda encontrada com maior frequência foi a poda de redução, e os principais defeitos encontrados foram galhos secos na copa, desequilíbrio e fissuras no tronco e raízes adventícias. Os defeitos ocorreram com maior frequência nas árvores podadas, podendose concluir que a poda influenciou na maior ocorrência de defeitos estruturais, sendo necessária a regularização da poda para que seja realizada exclusivamente por arboricultores certificados.
\end{abstract}

Palavras-chave: Figueira; Arborização urbana; Defeitos de árvores; Risco de queda de árvores.

\begin{abstract}
The knowledge of the structural defects that compromise the quality of urban afforestation and the pattern of the main species that make up the urban forest is fundamental for its management and planning, being able to avoid and reduce the risk of falling trees. Considering that pruning is the most common management practice in the established urban forest, and that Ficus benjamina trees are frequent in urban forests worldwide, this research aimed to determine the main structural defects that compromise the health and structure of these trees, found in the Urban Forest of the city of Itanhaém-SP, as well as the relationship between defects and the presence of pruning. For this, the trees were evaluated for frequency and type of pruning, the dendrometric variables were measured and the presence of defects was identified. As a result, the pruning found most frequently was the reduction pruning, and the main defects found were dry branches in the crown, imbalance and fissures in the trunk and adventitious roots. Defects occurred more frequently in pruned trees, and it can be concluded that pruning influenced the greater occurrence of structural defects, requiring regularization of pruning so that it is carried out exclusively by certified arboriculturists.
\end{abstract}

Keywords: Fig tree; Urban tree, Tree defects, Urban tree risk.

Recebido em 28.05.2021 e aceito em 20.07.2021

1 Engenheira Florestal, Me. Engenharia Florestal, Doutoranda do Programa de pós-graduação em Engenharia Florestal da Universidade Federal do Paraná. Curitiba/PR. E-mail: trbotelhomaria@gmail.com

2 Engenheira Florestal, Prof. Dr. da Universidade Federal do Paraná. Curitiba/PR. E-mail: dbiondi@ufpr.br

3 Engenheiro Florestal, Prof. Dr. da Universidade Federal do Paraná. Curitiba/PR. E-mail: alexandre.behling@gmail.com

4 Engenheiro Florestal, Prof. Dr. da Universidade Federal do Paraná. Curitiba/PR. E-mail: nilton.ufpr@gmail.com 


\section{INTRODUÇÃO}

A publicação de muitos estudos relacionados ao benefício da floresta urbana à qualidade de vida da população, tem incentivado a inclusão das árvores no meio urbano com objetivo de mitigar parte dos problemas oriundos da urbanização.

Toda vegetação (herbácea, arbustiva e arbórea) implantada ou remanescente em área urbana, encontrada em propriedades públicas ou privadas, são considerados componentes da floresta urbana, sendo a arborização de ruas, a vegetação mais próxima da população (BIONDI, 2015).

Uma das espécies arbóreas frequentemente utilizada na composição da arborização viária em todo mundo é o Ficus benjamina. A espécie pode ser encontrada desde as calçadas de Hong Kong, na China (JIM; CHEN, 2010) até nas calçadas da cidade do México (GUZMÁNMORALES et al., 2011) e de cidades brasileiras como São Paulo e Itanhaém (LUNDGREN et al., 2013; MARIA; ZAMPRONI; BIONDI, 2020).

A espécie pertence a família Moraceae e é nativa do sudeste da Ásia e da Oceania, descrita como uma espécie perene, ou sempre-verde, com copa globosa, com maior desenvolvimento em largura quando comparada à altura, podendo alcançar 10,0 $\mathrm{m}$ de altura, e comumente apresenta raízes adventícias (GUEVARA-ESCOBAR et al., 2007; STARR et al., 2019).

Maria, Zamproni e Biondi (2020) constataram que 42,9\% das árvores desta espécie apresentavam condições estruturais e fitossanitárias ruins, ocasionadas principalmente por podas inadequadas. As autoras enfatizam também, que para o manejo adequado destas árvores em calçadas, é necessário reunir informações pertinentes ao seu desenvolvimento e limitações no meio urbano, a fim de diminuir o comprometimento da estrutura e fitossanidade das árvores.

Nesse sentido, segundo a USDA (1992) existem sete defeitos estruturais capazes de comprometer o desenvolvimento e a sanidade de árvores urbanas, entre elas: rachaduras no tronco, problemas no sistema radicular, união fraca dos galhos, cancro, arquitetura de copa defeituosa, galhos mortos e apodrecimento do lenho (ataque de organismos xilófagos), todos estes defeitos são avaliados durante a classificação visual do risco de queda de acordo com protocolos nacionais (SEITZ, 2005) e pela sociedade internacional de arboricultura (SMILLEY; MATHENY; LILLY, 2011).

A identificação dos defeitos estruturais das árvores e a identificação da relação destas com o manejo por podas, é fundamental para direcionar a localização e espaços adequados para a implantação destas árvores e assim reduzir os conflitos e despesas com as mesmas e garantindo maior longevidade das árvores. 
Considerando o uso comum da espécie pelo mundo, é necessário compreender os principais conflitos do desenvolvimento desta no meio urbano. Segundo McPherson et al. (2017) a melhor forma de se manter as florestas urbanas saudáveis e resilientes, é pela clara compreensão das condições atuais das árvores e das ameaças ao seu desenvolvimento.

Assim, esta pesquisa teve por objetivo determinar os principais defeitos estruturais que comprometem a estrutura e sanidade das árvores de Ficus benjamina encontradas na Floresta urbana de Itanhaém - SP bem como a relação da frequência dos defeitos com a presença das podas.

\section{MATERIAL E MÉTODOS}

A presente pesquisa foi desenvolvida no município de Itanhaém (Figura 1), litoral sul do Estado de São Paulo, sendo o marco zero localizado sob as coordenadas $24^{\circ} 11^{\prime \prime}{ }^{\prime \prime}$ sul e 4647'22" oeste (MARIA; BIONDI; ZAMPRONI 2020).
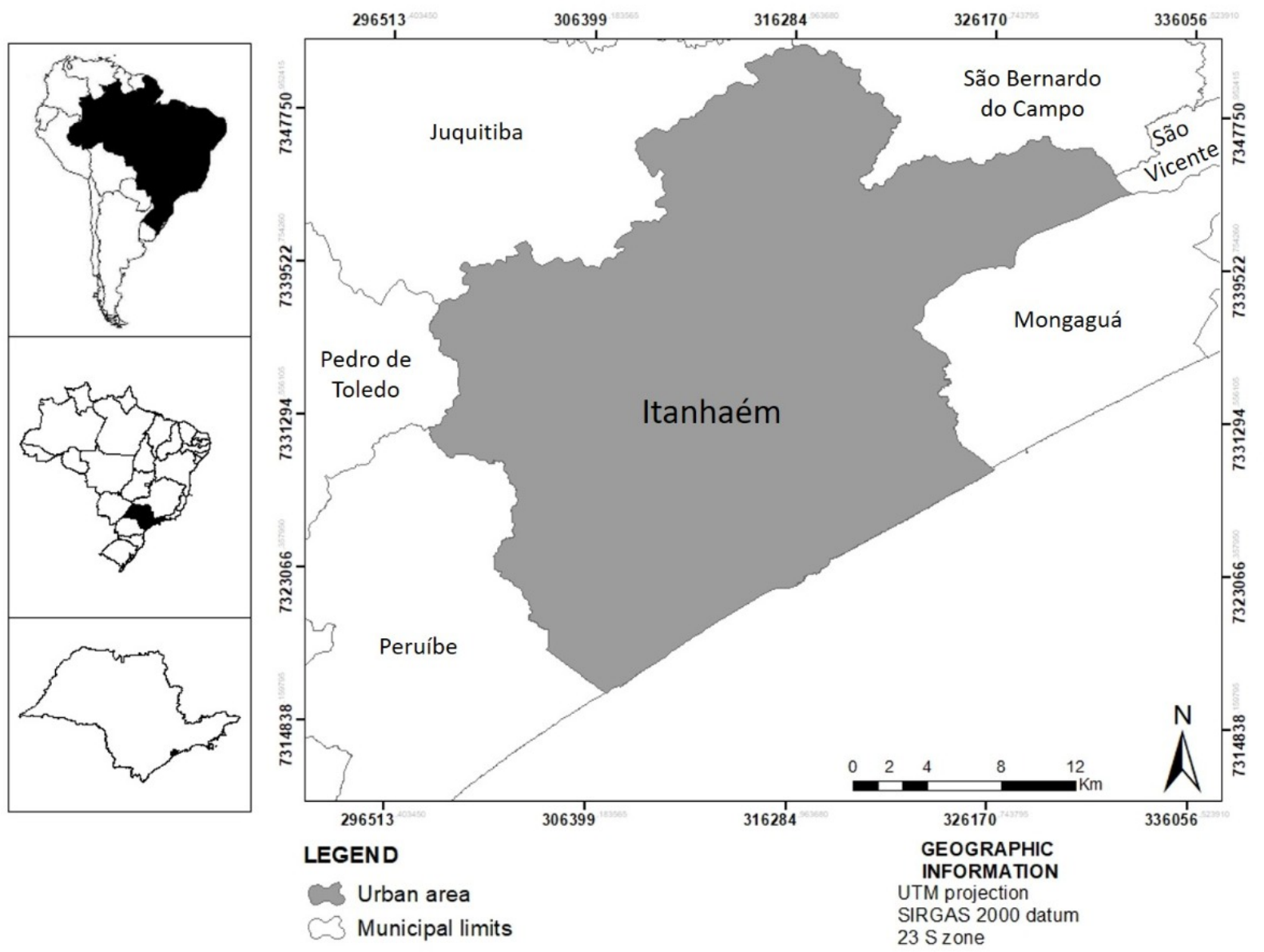

Figura 1. localização do município de Itanhaém-SP

Fonte (Maria; Biondi; Zamproni, 2020).

Figure 1. Itanhaém-SP location 
O clima característico do município é do tipo Af, segundo a classificação de Köppen, descrito como clima tropical sem estação seca, com precipitação média mensal maior que 60 $\mathrm{mm}$ e temperatura média do mês mais frio igual a $18^{\circ} \mathrm{C}$ (ALVAREZ et al., 2014).

O município integra o bioma Mata Atlântica e na área urbana, Maria, Zamproni e Biondi (2020) constataram a presença de 18.128 árvores em calçadas, sendo que $16,8 \%$ das árvores eram de Ficus benjamina.

Para atender os objetivos da pesquisa, foram selecionadas árvores com altura superior a 2,5 m, avaliadas em quatro etapas, sendo: identificação da presença e modalidade de poda, mensuração das variáveis dendrométricas das árvores, identificação da presença de defeitos estruturais e avaliação da associação entre a poda e os defeitos estruturais.

Para avaliar a primeira etapa quanto a presença da poda foi considerada a identificação de presença de vestígios de seções de corte e compartimentalização nos galhos e tronco das árvores (Figura 2), além da comparação entre a arquitetura naturalmente globosa da copa e a arquitetura atual, para identificar o tipo de poda realizada, utilizando como base os modelos de poda descritos pela ABNT NBR 16246-1 e as podas comumente aplicadas no município (Quadro 1).
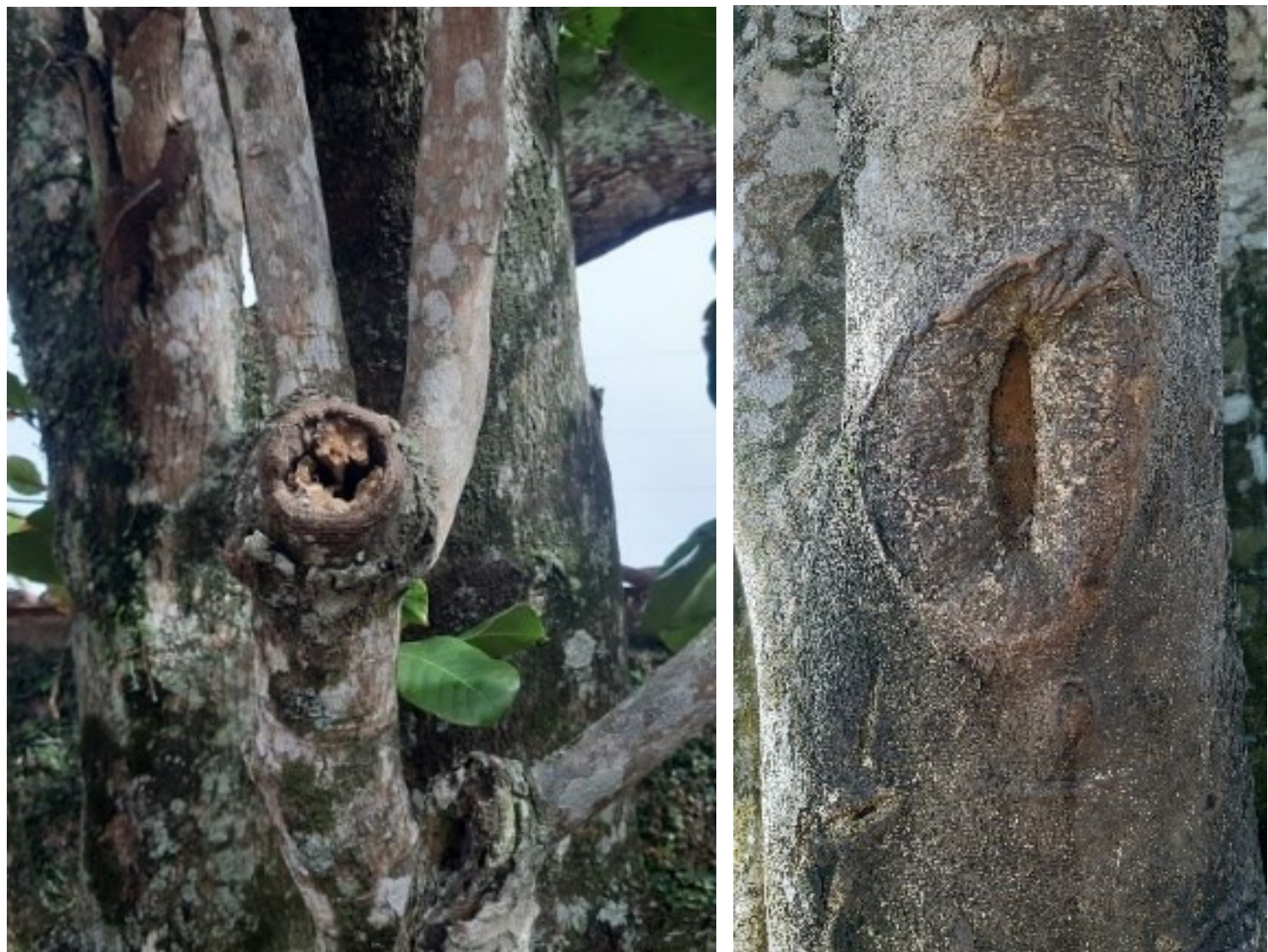

Figura 2. Indícios de seções de corte e compartimentalização causados por podas

Figure 2. Evidence of cutting and compartmentalization caused by pruning 
Quadro 1. Classificação das modalidades de poda comumente realizadas em Ficus benjamina

Chart 1. Classification of the pruning modalities commonly practiced in Ficus benjamina

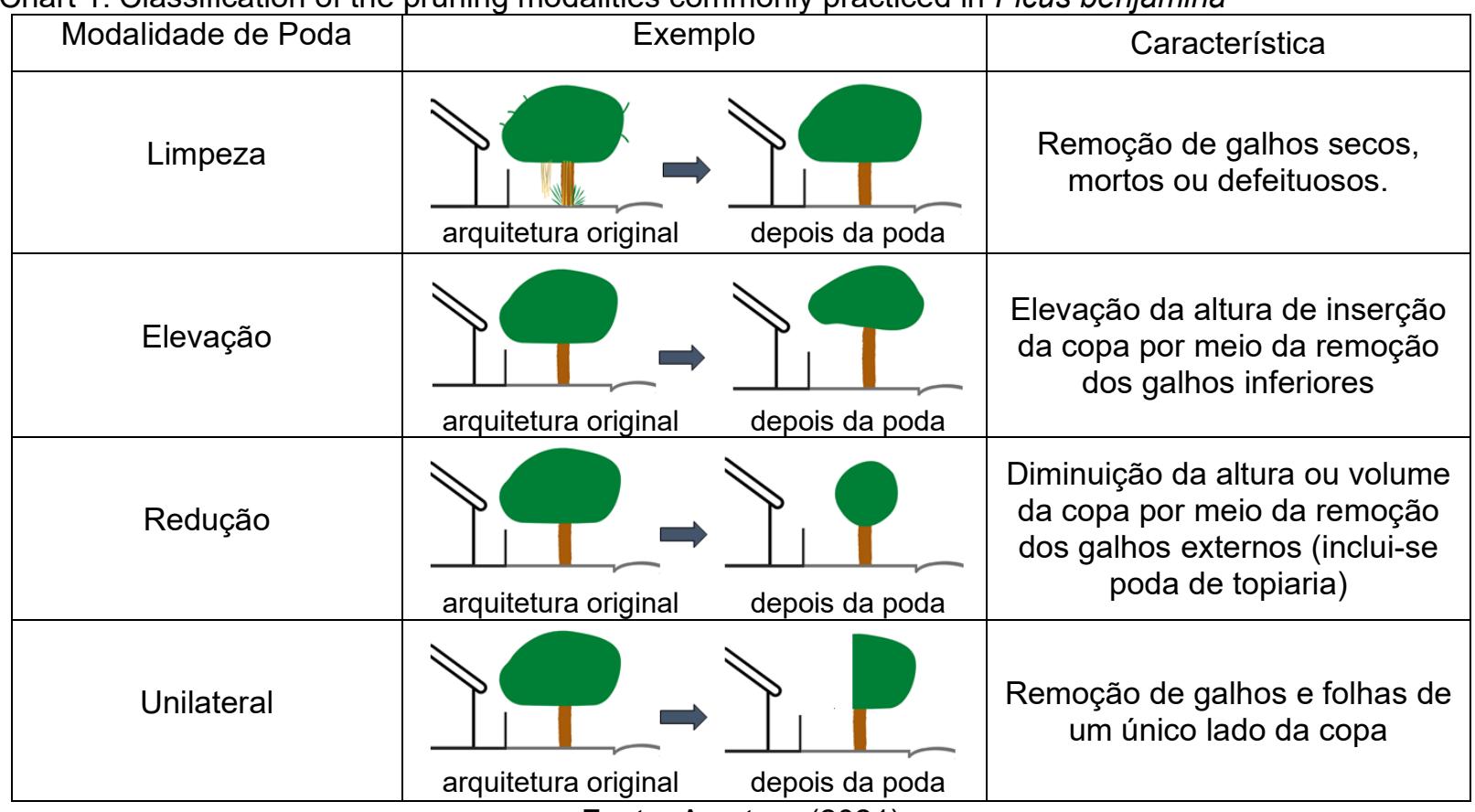

Fonte: A autora (2021)

As variáveis dendrométricas, mensuradas na segunda etapa, para identificar a influência da poda no porte das árvores foram: altura total (HT), altura da primeira bifurcação (Hbif), diâmetro à altura do peito (DAP) e raio de copa $(\mathrm{RC})$ que posteriormente foi utilizado para o cálculo da área de copa.

Para a terceira etapa, foram avaliadas a presença ou ausência dos defeitos estruturais, considerando como base as sete classes de Defeitos estruturais de árvores urbanas, descritas pelo Serviço Florestal Americano (1992), sendo as características e parâmetros de cada defeito avaliados conforme descrito na tabela 1.

As coletas dos dados referentes às três primeiras etapas da avaliação foram realizadas a campo com uso de uso de formulário eletrônico por meio de aparelho celular de sistema Android, pelo software ODKcollect ${ }^{\circledR}$. A inclinação do tronco foi mensurada com clinômetro digital para Android pelo software Clinometer $囚$. As variáveis métricas foram mensuradas com uso de trena, fita métrica e hipsômetro de Blume leiss. Posteriormente todos os dados foram armazenados e processados no software Excel ${ }^{\circledR}$.

Para a quarta etapa, responsável pela identificação da associação entre os defeitos encontrados e a presença de poda, foi utilizado o software estatístico WEKA® por meio do algorítimo Apriori, utilizado para determinar a associação de variáveis não paramétricas/qualitativas de quaisquer bancos de dados, sendo aplicado com restrição de associações de no mínimo $90 \%$ de confiança e geração de 50 regras. 
Tabela 1. Características avaliadas externamente de forma visual para identificar a presença de defeitos estruturais nas árvores

Table 1. Characteristics evaluated to identify the presence of structural defects in the trees

\begin{tabular}{|c|c|c|}
\hline $\begin{array}{c}\text { Classe de } \\
\text { defeito }\end{array}$ & Característica avaliada & Parâmetros visuais de identificação \\
\hline $\begin{array}{l}\text { Galhos mortos } \\
\text { ou árvore em } \\
\text { die-back } \\
\text { (declínio) }\end{array}$ & Folhagem esparsa (copa) & $\begin{array}{l}\text { Galhos secos, com coloração escurecida com } \\
\text { presença ou não de manchas e fungos no todo } \\
\text { ou em partes. } \\
\text { Folhagem em quantidade inferior ao comum } \\
\text { para a espécie }\end{array}$ \\
\hline $\begin{array}{l}\text { União fraca do } \\
\text { tronco ou dos } \\
\text { galhos }\end{array}$ & $\begin{array}{c}\text { Brotações epicórmicas (copa e } \\
\text { tronco) }\end{array}$ & $\begin{array}{l}\text { Presença de brotações epicórmicas na copa e } \\
\text { no tronco, caracterizada pela emissão de } \\
\text { brotos de crescimento vertical, emitidos como } \\
\text { forma compensatória pela perda de taxa } \\
\text { fotossintética; } \\
\text { Bifurcações primárias ou ao longo do tronco, } \\
\text { em formato "V" ou forquilhas, com dois galhos } \\
\text { codominantes ou casca inclusa. }\end{array}$ \\
\hline Rachaduras & Rachaduras (tronco e galhos) & $\begin{array}{l}\text { Presença de fenda ou separação vertical na } \\
\text { casca externa do tronco ou galhos com } \\
\text { profundidade que atingisse o lenho. }\end{array}$ \\
\hline Cancro & Cavidades (tronco e raiz) & $\begin{array}{l}\text { Cavidades vistas externamente com } \\
\text { profundidade maior que } 30 \% \text { do diâmetro do } \\
\text { tronco elou com profundidade maior que } 5 \mathrm{~cm} \\
\text { nas raízes visíveis externamente (ocos internos } \\
\text { sem externalização não foram avaliados) } \\
\text { lesões que ocupam mais de } 40 \% \text { do perímetro } \\
\text { da região afetada do tronco e/ou lesão com } \\
\text { diâmetro maior que } 10 \mathrm{~cm} \text { nas raízes visíveis } \\
\text { externamente }\end{array}$ \\
\hline $\begin{array}{l}\text { Arquitetura } \\
\text { alterada }\end{array}$ & Desequilíbrio (copa e tronco) & $\begin{array}{l}\text { Quando a distribuição dos galhos não está } \\
\text { equilibrada com relação ao eixo do tronco, } \\
\text { causando formato irregular ou desequilibrado } \\
\text { na copa; quando o tronco apresenta } \\
\text { desenvolvimento com inclinação maior que } 10^{\circ} \\
\text { a partir do eixo vertical } \\
\text { Presença de ervas de passarinho ou plantas } \\
\text { parasitas na copa das árvores }\end{array}$ \\
\hline $\begin{array}{l}\text { Problemas no } \\
\text { sistema } \\
\text { radicular }\end{array}$ & Raízes adventícias & $\begin{array}{l}\text { Presença de raízes aéreas oriundas das folhas, } \\
\text { galhos ou tronco; } \\
\text { Afloramento das raízes na superfície } \\
\text { observadas também pelas rachaduras no solo } \\
\text { ou calçadas, causadas por solos com } \\
\text { deficiência nutricional ou solos compactados; } \\
\text { Identificação de vestígios de poda das raízes } \\
\text { de ancoramento }\end{array}$ \\
\hline $\begin{array}{l}\text { Apodrecimento } \\
\text { do lenho }\end{array}$ & Fungos & $\begin{array}{l}\text { Presença de corpos de frutificação, manchas } \\
\text { de fungos ou amolecimento do lenho } \\
\text { Presença do inseto, ninhos, galerias ou } \\
\text { vestígios de insetos como cupins, formigas e } \\
\text { abelhas carpinteiras }\end{array}$ \\
\hline
\end{tabular}




\section{RESULTADOS E DISCUSSÃO}

Foram avaliados 100 indivíduos adultos de Ficus benjamina, dos quais $70 \%$ apresentavam vestígios de poda (Figura 3), sendo a poda de redução a mais frequente.

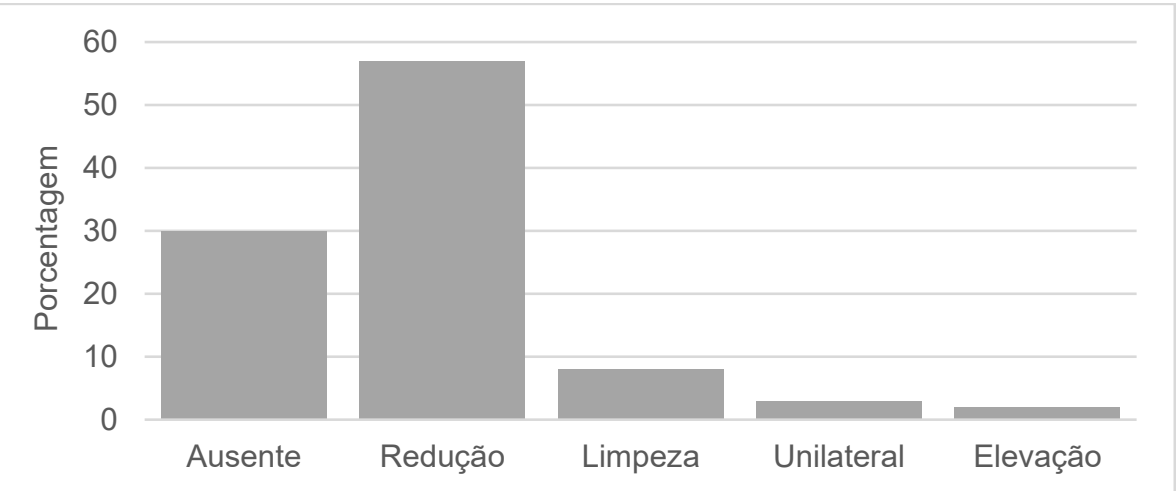

Figura 3. Modalidade de podas realizadas em Ficus benjamina

Figure 3. Pruning modality practiced in Ficus benjamina

A poda de redução visa diminuir as dimensões da copa para atenuar os conflitos da mesma com o mobiliário. Porém, a redução de copa nessa espécie (57\%) é utilizada principalmente pela prática de ornamentação, mantendo a copa em formato redondo ou quadrado.

Analisando as diferenças nos padrões dendrométricos da espécie, foi possível verificar que a poda pode ter influenciado diretamente no porte das árvores de Ficus benjamina (Tabela 2) que obtiveram menor altura, DAP e raio de copa quando podadas.

Tabela 2. Variabilidade das características dendrométricas em Ficus benjamina Table 2. Variability of dendrometric characteristics in Ficus benjamina

\begin{tabular}{lrrrrrrrr}
\hline \multirow{2}{*}{ Variável } & \multicolumn{4}{c}{ Sem poda } & \multicolumn{5}{c}{ Com poda } \\
\cline { 2 - 9 } & Mín. & Médio & Máx. & Cv (\%) & Mín. & médio & Máx. & Cv (\%) \\
\hline Ht (m) & 1,9 & 9,4 & 15,0 & 39,36 & 1,6 & 3,62 & 8,0 & 39,50 \\
Hbif (m) & 0 & 2,0 & 3,5 & 46,89 & 0 & 0,7 & 1,9 & 65,06 \\
DAP (cm) & 5,0 & 76,7 & 146,4 & 542,37 & 2,0 & 15,0 & 73,2 & 86,88 \\
Rc (m) & 0,81 & 5,0 & 10,0 & 52,60 & 0,44 & 1,8 & 4,75 & 51,67 \\
AC (m) & 2,55 & 15,7 & 31,4 & 52,67 & 1,37 & 5,5 & 14,9 & 53,36 \\
\hline
\end{tabular}

NOTA: Ht (altura total); Hbif (altura da primeira bifurcação); DAP (diâmetro à altura do peito); Rc (raio de copa); AC (área de copa).

A variável com maior coeficiente de variação das árvores de Ficus benjamina foi o DAP, tanto para as árvores podadas, quanto para as árvores não podadas, o que pode indicar a ocorrência de diversas idades das árvores desta espécie no município (Figura 4). 


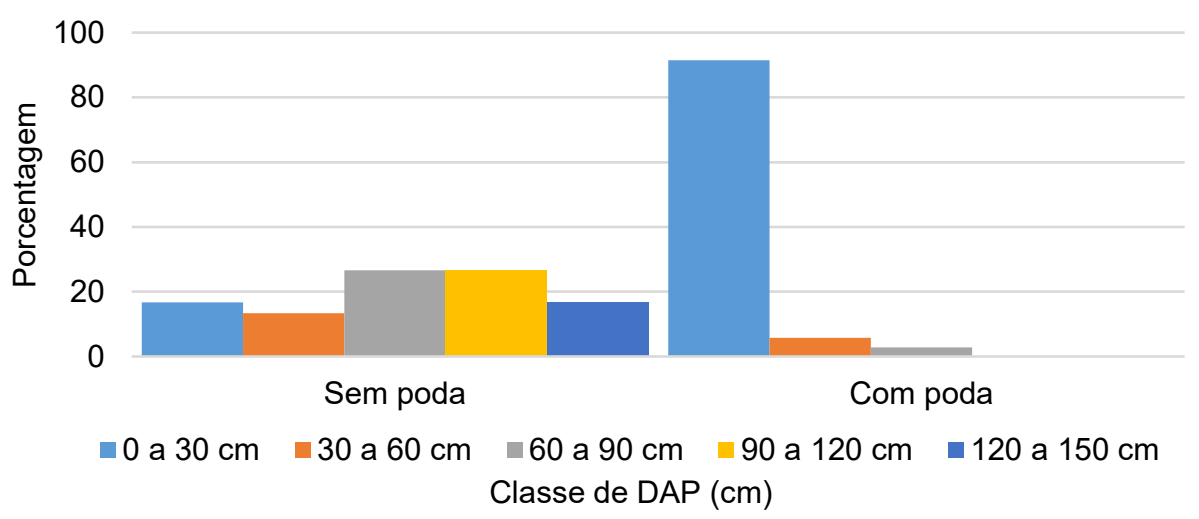

Figura 4. Classes de diâmetro de Ficus benjamina em porcentagem

Figure 4 Diameter classes of Ficus benjamina in percentage

Observa-se que poucas árvores podadas (8,6\%) apresentavam o DAP superior a 30 $\mathrm{cm}$, diferentemente da característica observada para árvores sem poda. Em estudo do desenvolvimento da espécie em Santarém no Pará (FERNANDES; XIMENES, 2020) as árvores em calçadas do gênero Ficus apresentavam em sua maioria, DAP na classe de 45 a $55 \mathrm{~cm}$, seguido da classe de DAP superior a $100 \mathrm{~cm}$.

O resultado do menor DAP médio encontrado em Itanhaém indica que as árvores apresentam o declínio precoce, ou seja, uma queda de vigor causado por fatores que inerentes à idade das plantas, devido às podas de topiaria/redução, que são realizadas com frequência pela própria população, para conter o crescimento das árvores de forma que se adequem ao espaço que ocupam.

Embora a execução das podas seja recomendada para as árvores ainda jovens, a frequência de podas pode acabam comprometendo a sanidade das árvores, devido à excessiva exposição do lenho ao ambiente, propiciando a sua degradação (GILMAN; GRABOSKY, 2006).

Foi possível verificar que o manejo desta espécie pela poda ocorre principalmente nas árvores menores, com DAP na classe de 0 a $10 \mathrm{~cm}$, enquanto que as árvores sem poda apresentam maior concentração nas classes entre 60 e $120 \mathrm{~cm}$. Outro fator determinante para a poda foi a largura de calçada, onde a largura média da calçada das árvores podadas foi de 2,87 m e para as árvores não podadas foi de 12,94 m (Figura 5). Demonstrando que a poda na maioria dos casos, se dá na tentativa de conciliar o porte das árvores com o espaço à elas destinado. 


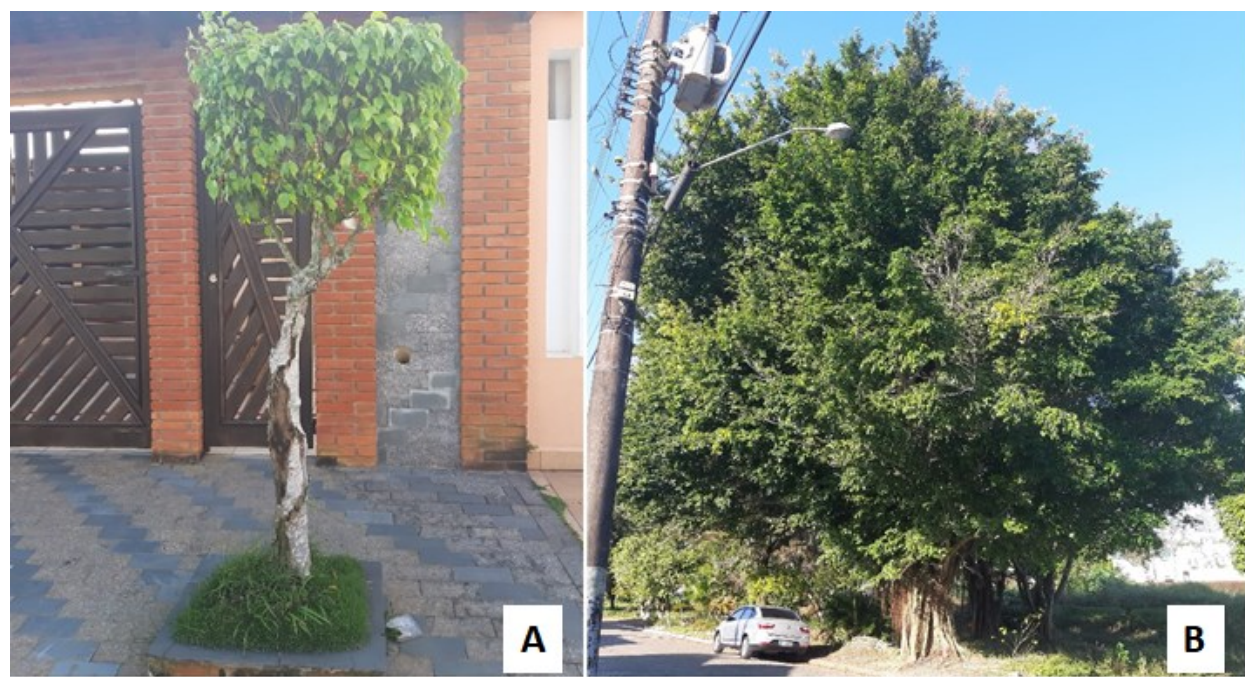

Figura 5. Diferentes classes diâmetro à altura do peito de Ficus benjamina em a) árvore jovem podada em calçada com largura de $3,0 \mathrm{~m}$; b) árvore adulta não podada em calçada com largura superior a $10,0 \mathrm{~m}$.

Figure 5. Different diameter's at breast height classes of Ficus benjamina in a) young tree pruned on a sidewalk with a width of $3.0 \mathrm{~m}$; b) unpruned adult tree on a sidewalk with a width greater than $10.0 \mathrm{~m}$.

A altura das árvores de Ficus benjamina também foi bastante restringida pelas podas, já que a altura média das árvores podadas foi menor que a metade da altura média das árvores não podadas (Figura 6). Sreetheran, Adnan e Azuar (2011) avaliando o risco de queda da arbprização viária na Malásia, identificaram também que a frequência da poda de redução é uma pratica comum por ser considerada como a melhor maneira de reduzir a altura de uma árvore e consequentemente os seus conflitos aéreos. Nesse sentido, foi possível verificar que $90 \%$ das árvores podadas estavam na classe de distribuição hipsométrica de 0 a $6 \mathrm{~m}$, caracterizando como árvores ainda com pequeno porte ou em estado jovem.

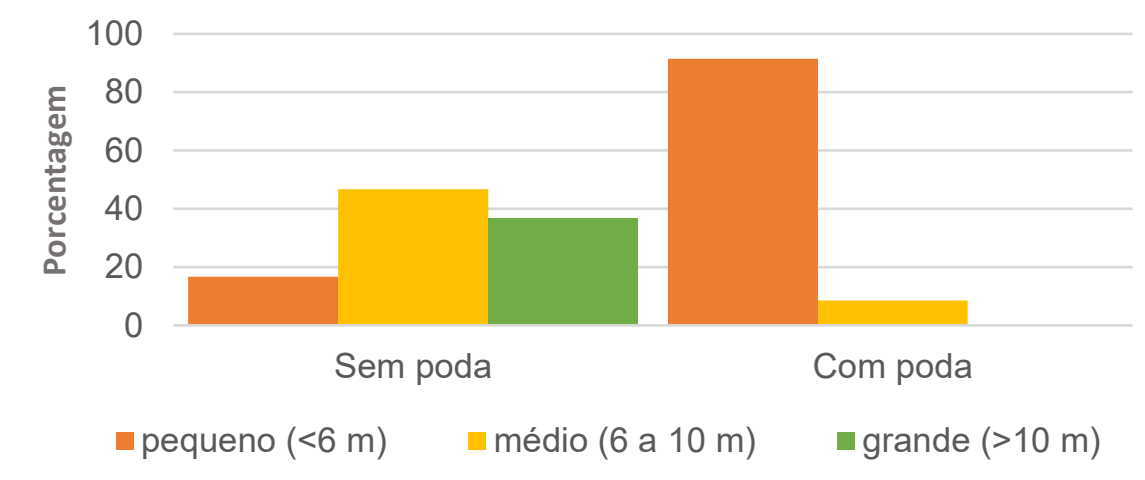

Figura 6. Classificação do porte de Ficus benjamina em porcentagem

Figure 6. Classification of the size of Ficus benjamina in percentage

Para a espécie, a poda de redução, que é realizada com frequência pelos próprios moradores, pode ter sido utilizada não apenas para ornamentação, mas também como 
prevenção dos conflitos com as linhas de transmissão de baixa tensão, com altura de 6,0 m do solo.

Quanto à altura da primeira bifurcação foi possível verificar que todas as árvores de Ficus benjamina que sofreram poda apresentavam altura da primeira bifurcação abaixo de 1,80m (Figura 7), altura recomendada por Lima Neto et al. (2012) para evitar a interferência da copa na circulação de pedestres.

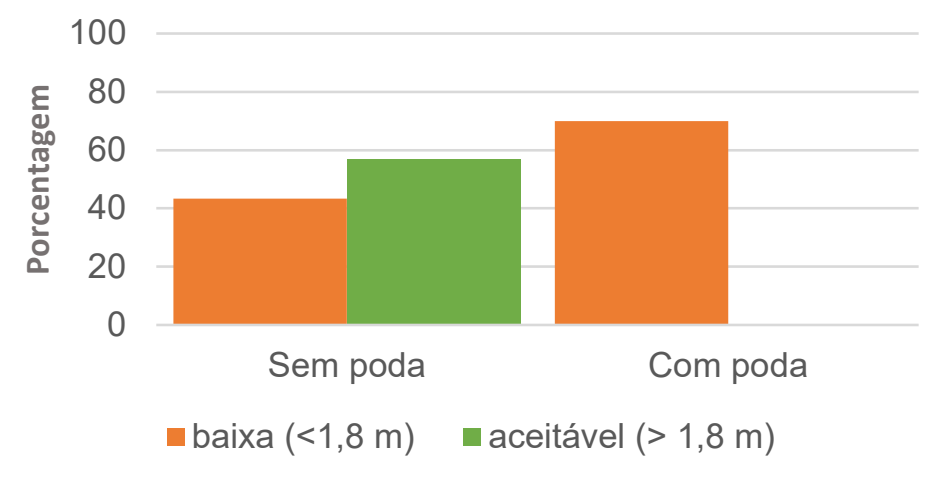

Figura 7. Classificação da altura de bifurcação de Ficus benjamina em porcentagem Figure 7. Classification of Ficus benjamina bifurcation height in percentage

Embora a poda seja uma das formas de melhorar a qualidade das árvores com relação à altura de bifurcação (USDA, 1992), esta não foi levada em consideração na execução das podas que é realizada apenas para a redução e ornamentação da copa, o que faz com que as árvores acabem atrapalhando a circulação de pedestres nas calçadas.

Observou-se que as árvores não podadas apresentavam, em sua maioria (73,4\%), uma área de copa grande (acima de $26,5 \mathrm{~m}^{2}$ ), enquanto que para as árvores podadas a maioria apresentava área de copas pequenas e médias (Figura 8). Bobrowski e Biondi (2012) enfatizam que a copa concentra os principais benefícios almejados pela implantação das árvores urbanas, como a melhoria do microclima e infiltração de água da chuva. Nesse sentido, quando comparados os valores médios da área de copa das árvores com e sem poda, pode-se observar uma redução de quase $70 \%$ da área de copa das árvores podadas, o que pode implicar diretamente na redução dos benefícios proporcionados pelas árvores. 


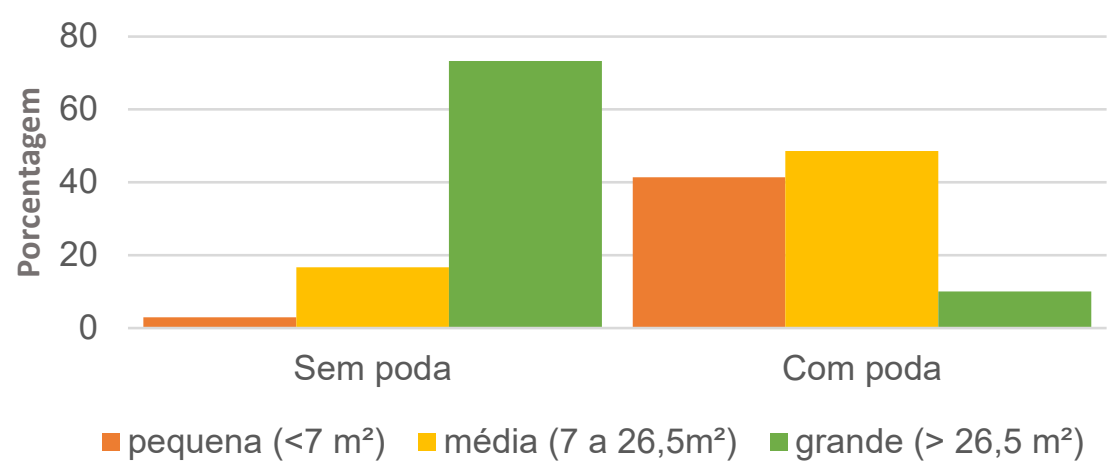

Figura 8. Classes de área de copa de Ficus benjamina em porcentagem

Figure 8. Classes of Ficus benjamina canopy area in percentage

Imran et al. (2014) descrevem como porte característico da espécie, uma copa extensa, com até 10,0 metros de diâmetro. Seguindo este padrão, a área média da copa das árvores livres de intervenção, seria de aproximadamente 31,0 metros.

Para as árvores avaliadas nesta pesquisa, o defeito mais frequente na copa foi a presença de galhos secos/mortos, verificado em $90 \%$ das árvores com e sem podas (Figura 9). A presença de galhos secos no interior da copa pode ocorrer devido à alta densidade da copa que não permite a entrada de luz nos ramos localizados na parte mais interna da copa, diminuindo a capacidade fotossintética e consequentemente desvitalizando esses galhos, produzindo futuramente uma desrama natural dos galhos secos e mortos (GILMAN, 2012).

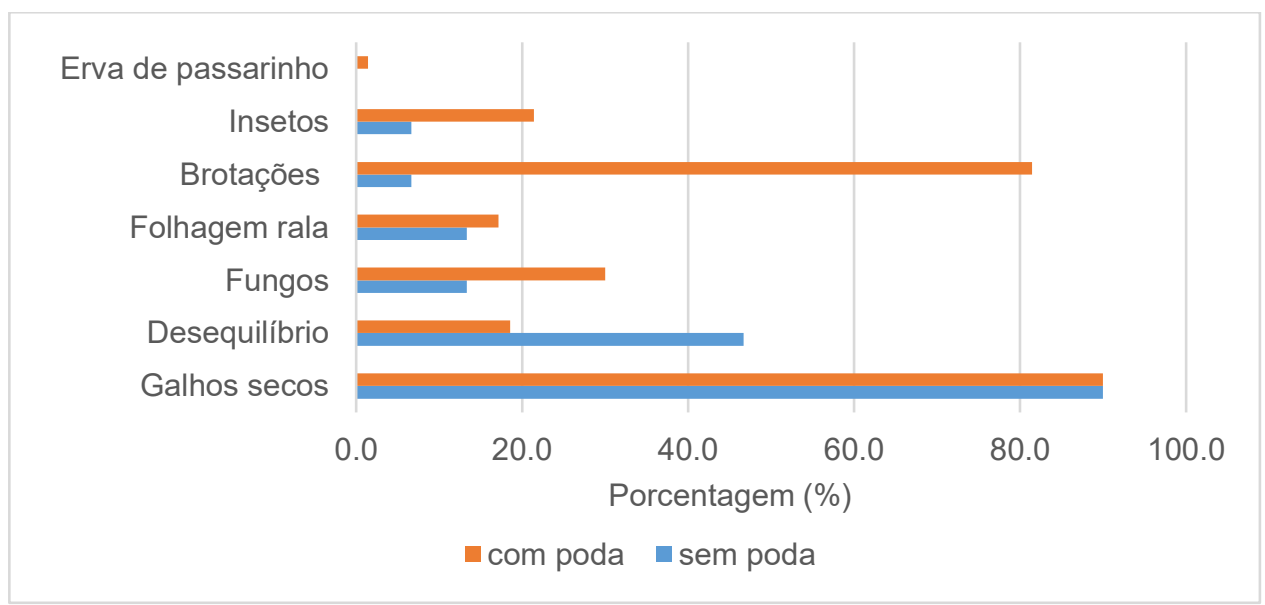

Figura 9. Defeitos na copa das árvores de Ficus benjamina em porcentagem

Figure 9. Defects in the canopy of Ficus benjamina in percentage

Sreetheran, Adnan e Azuar (2011) também observaram que os galhos secos ou mortos foram os defeitos mais frequentes na arborização e que embora não seja uma variável de elevado risco, ela pode ter seu risco potencializado caso a árvore esteja inserida em vias de alta frequência. 
O segundo defeito mais frequente nas árvores com poda foram as brotações epicórmicas (Figura 9A), enquanto que o defeito mais frequente das árvores não podadas foi o desequilíbrio de copa (Figura 9B). Nesses casos, se vê a poda como causa e também como solução de correção desse defeito estrutural, onde é necessário realizar a condução de um dos ramos da brotação epicórmica como ramo de crescimento principal do galho anteriormente removido.
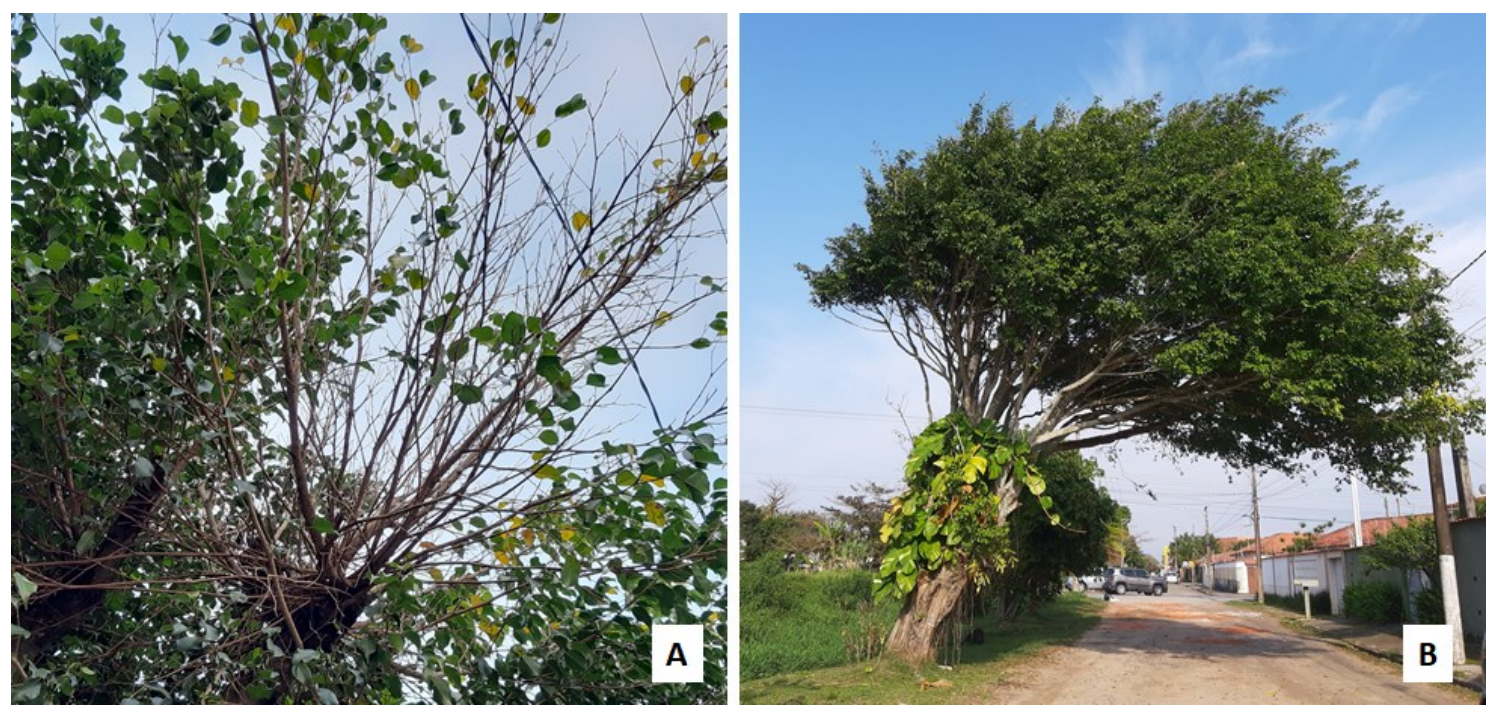

Figura 10. Defeitos frequentes em Ficus benjamina; a) brotações epicórmicas; b) desequilíbrio da árvore Figure 10. Frequent defects in Ficus benjamina; a) epicormic shoots; b) tree imbalance

Gilman (2012) afirma que as brotações epicórmicas surgem como uma resposta natural da árvore às podas severas, onde a perda do material fotossintético da copa induz a quebra da dormência das gemas latentes com intuito de compensar a área assimilatória perdida pela árvore. Assim, nesse caso a emissão dos ramos com ligação fraca, tem como causa a poda.

Em contrapartida Guimarães e Cardoso Junior (2019) afirmam que dependendo da situação, a árvore pode apresentar risco iminente de queda por causa do desequilíbrio na copa. Nesses casos a poda poderia ser aplicada de forma preventiva na correção do equilíbrio, diminuindo a probabilidade de tombamento pelo peso unilateral da copa.

O defeito mais frequente no tronco foram as rachaduras (Figura 11), tanto para as árvores podadas (50\%), quanto para as árvores não podadas $(43,3 \%)$. 


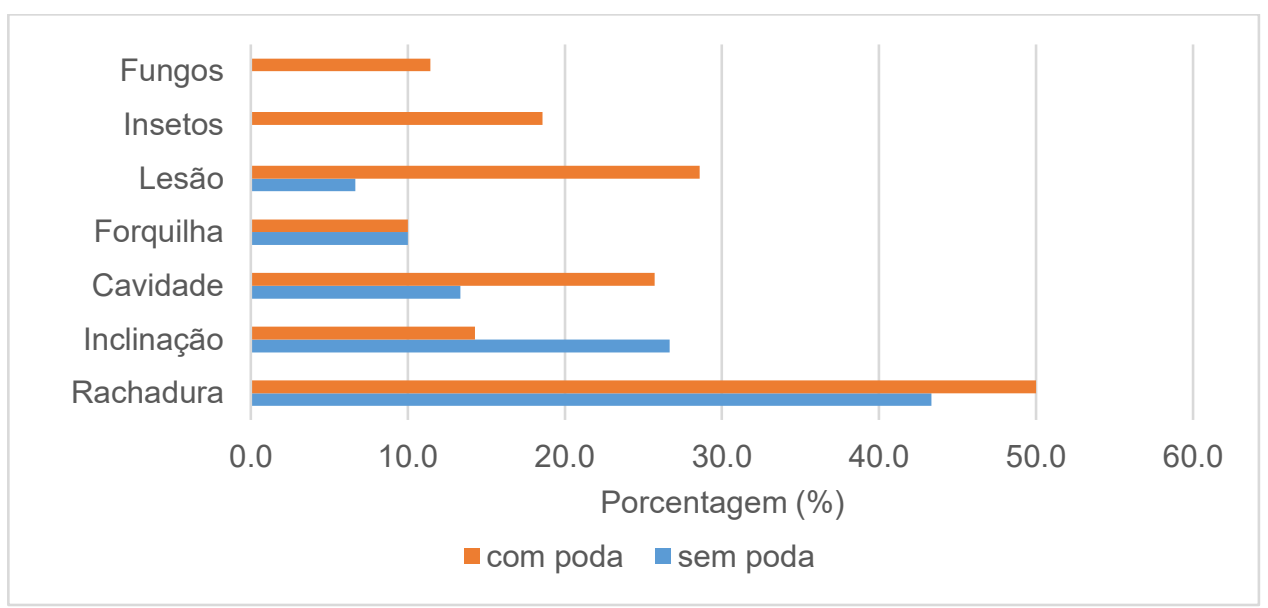

Figura 11. Defeitos no tronco das árvores de Ficus benjamina em porcentagem Figure 11. Defects in the trunk of Ficus benjamina trees in percentage

Os defeitos de cavidades e rachaduras também foram os defeitos mais frequentes nos troncos de árvores avaliadas na arborização de Hong Kong e tiveram forte influência negativa na fitossanidade das árvores (JIM; ZHANG, 2013)

Foi observado que no ponto de secção das rachaduras, a árvore iniciava a emissão de raízes adventícias (Figura 12), porém, não é possível afirmar se as rachaduras são consequências ou causas da emissão das raízes adventícias. A emissão dessas raízes é comum para a espécie (GUEVARA-ESCOBAR, 2007) e demonstra problemas de ancoragem e sustentação das árvores, que acabam causando uma auto enxertia da árvore (JIM; CHEN, 2010).

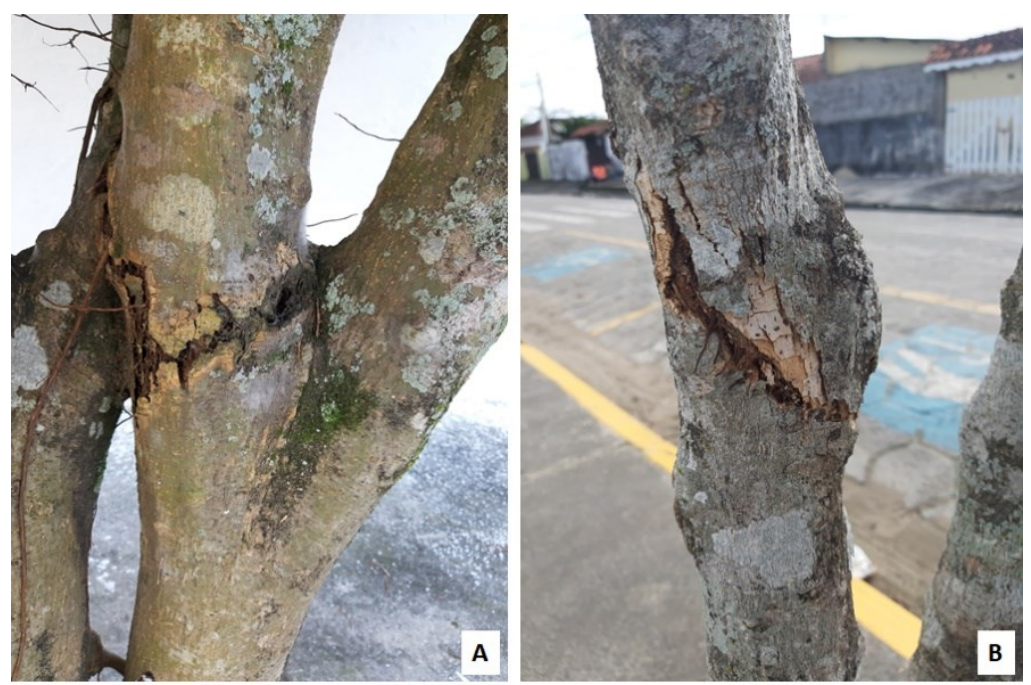

Figura 12. Presença de rachaduras em Ficus benjamina a) na bifurcação; b) ao longo do tronco Figure 12 Presence of cracks in Ficus benjamina a) at the fork; b) along the trunk

O segundo defeito mais frequente no tronco das árvores de Ficus benjamina não podadas foi a inclinação do tronco, que se torna um defeito estrutural, quando a inclinação é maior que $10^{\circ}$ a partir do eixo vertical. Este defeito ocorreu em $26,7 \%$ das árvores avaliadas, que 
tiveram uma inclinação média de $25^{\circ}$, possivelmente como uma consequência do peso das copas desequilibradas ou do solo arenoso no município. (FIGURA 13).

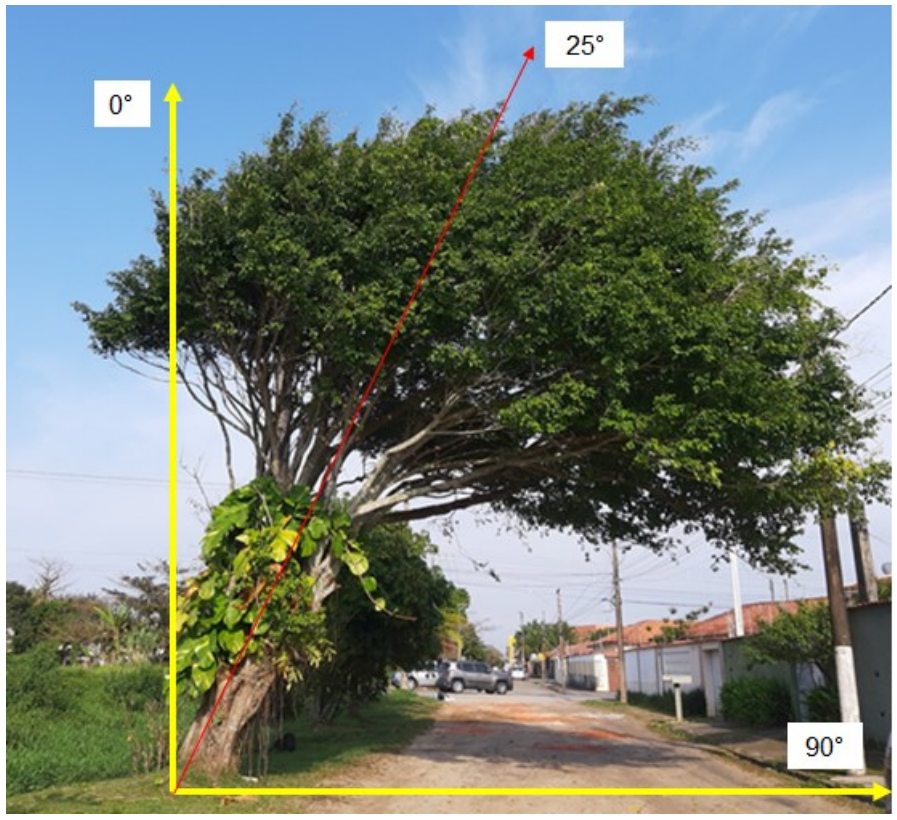

Figura 13. Exemplar de Ficus benjamina sem poda e com inclinação de $25^{\circ}$ Figure 13. Example of Ficus benjamina without pruning and inclined at $25^{\circ}$

Para as árvores de Ficus benjamina podadas, o segundo defeito mais frequente no tronco das árvores foram as lesões. Apesar da maioria dos casos de lesão no tronco de árvores urbanas estarem associadas às injúrias mecânicas causadas por podas mau-executadas, sem técnicas ou ferramentas adequadas (SANTOS et al., 2019), que ultrapassam a zona de inserção dos galhos, as árvores avaliadas em Itanhaém, apresentaram lesão causada pela própria emissão das raízes adventícias, que lesionavam a casca externa, gerando um cancro (FIGURA 14).

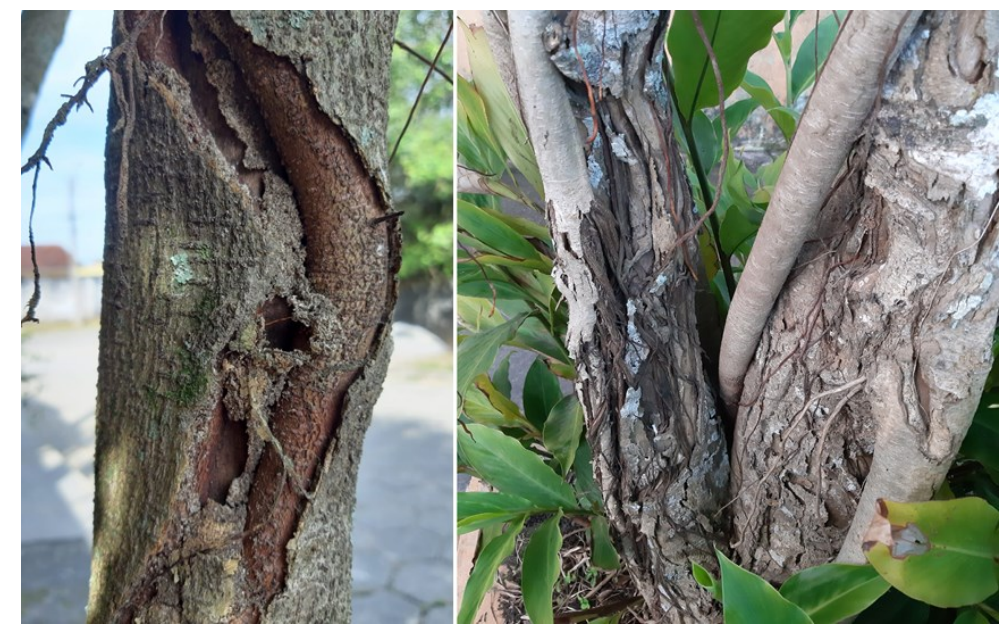

Figura 14. Exemplares de Ficus benjamina com lesões no tronco

Figure 14. Individuals of Ficus benjamina with trunk injuries 
$\mathrm{Na}$ avaliação da base e raízes das árvores de Ficus benjamina, as raízes adventícias foram o defeito mais frequente para as árvores com e sem poda, seguidos pela formação de fissura no solo (Figura 15).

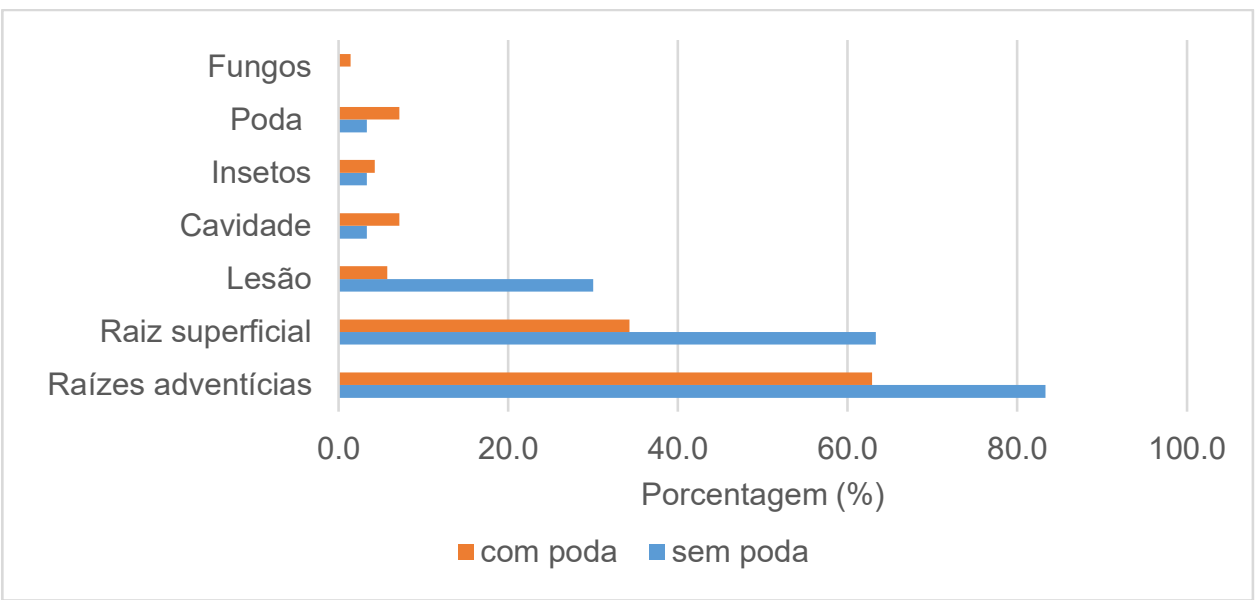

Figura 15. Defeitos na base do tronco e nas raízes das árvores de Ficus benjamina em porcentagem Figure 15. Defects in the base of the trunk and in the roots of Ficus benjamina trees in percentage

Relatos de danos ocasionados pelas raízes adventícias de Ficus benjamina em Itanhaém (Figura 16) também são frequentes em pesquisas da arborização urbana de outras cidades (MARTELLI; BARBOSA JÚNIOR, 2010; ALBERTIN et al., 2011, LUNDGREN et al., 2013). Vargas-Gárzon e Molina-Prieto (2012) citam ainda que os prejuízos causados pelas raízes destas árvores na Colômbia, Brasil e México, vão além de danos às calçadas, podendo prejudicar galerias de água e esgoto.

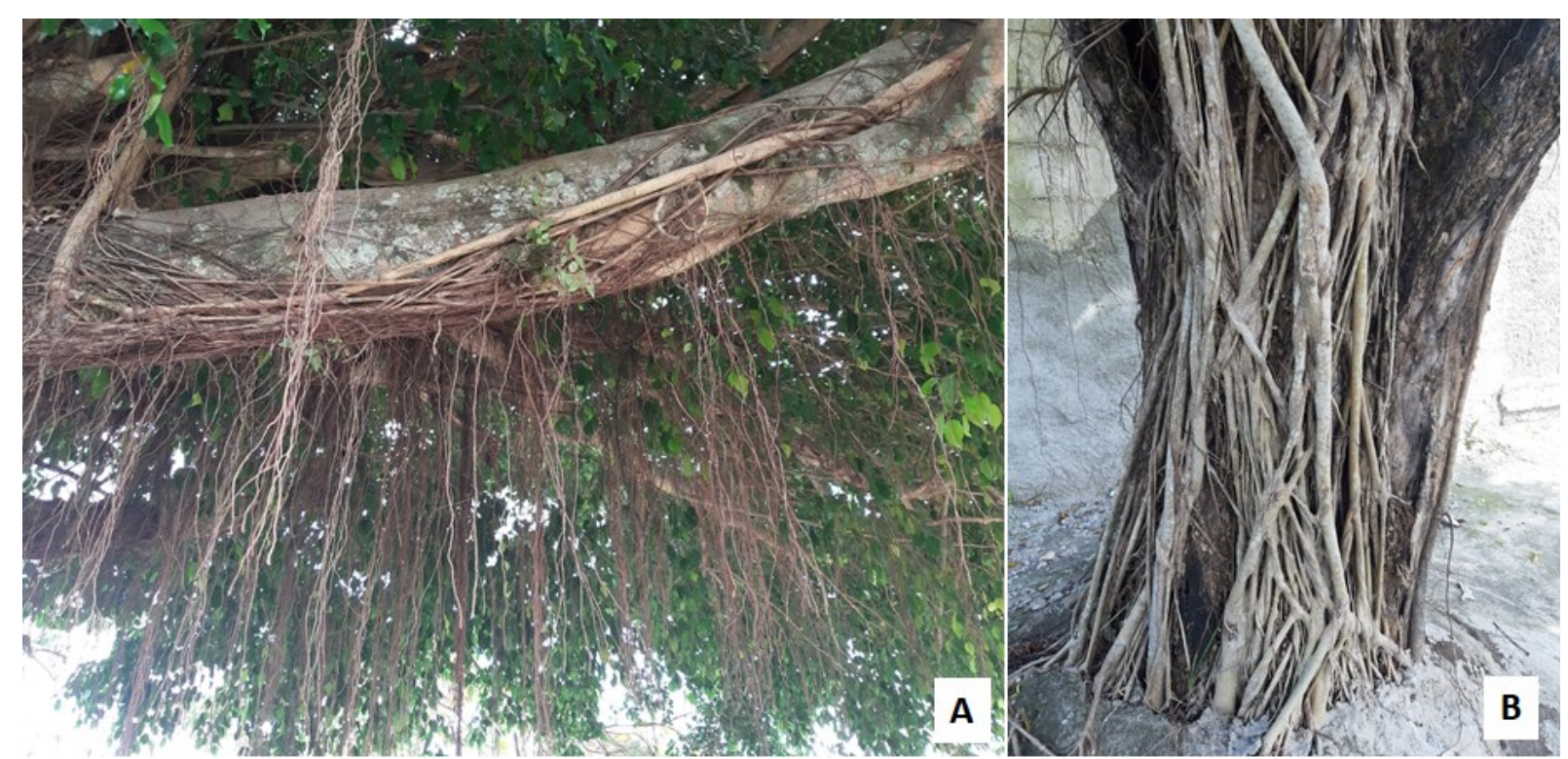

Figura 15. Raízes adventícias de Ficus benjamina a) nos galhos; b) no tronco

Figure 15. Adventitious roots of Ficus benjamina a) on branches; b) on the trunk 
Avaliando a presença de defeitos nas árvores foi possível concluir que cada árvore de Ficus benjamina apresentou em média 5 defeitos estruturais. Quando avaliado separadamente as árvores podadas e não podadas, observamos que as árvores sem poda na copa apresentavam em média 2 defeitos na copa, 1 no tronco e 2 nas raízes totalizando em média 5 defeitos, enquanto que as podadas apresentavam em média 3 defeitos na copa, 2 defeitos no tronco e 1 defeito nas raízes, totalizando em média 6 defeitos.

Fica claro a partir dos resultados que a poda contribui com a presença de defeitos na copa e no tronco, mas reduziu a quantidade de defeitos nas raízes, possivelmente devido à transferia exclusiva de energia da árvore para manutenção da copa e não para a produção das raízes. Ainda assim, a quantidade de defeitos encontrados nas árvores avaliadas, mesmo as podadas, foi menor do que a encontrada por Jim e Zhang (2013) que observaram a presença de 8 defeitos nas árvores de diferentes espécies avaliadas em Hong Kong.

Em todas as partes da árvore, foi possível verificar a incidência de fungos e insetos para as árvores com poda. Entre os insetos frequentes nas árvores de Ficus benjamina, destacam-se principalmente os tripes, que atingiram $32 \%$ das árvores avaliadas e os cupins, causando danos à $15 \%$ das árvores (Figura 16).

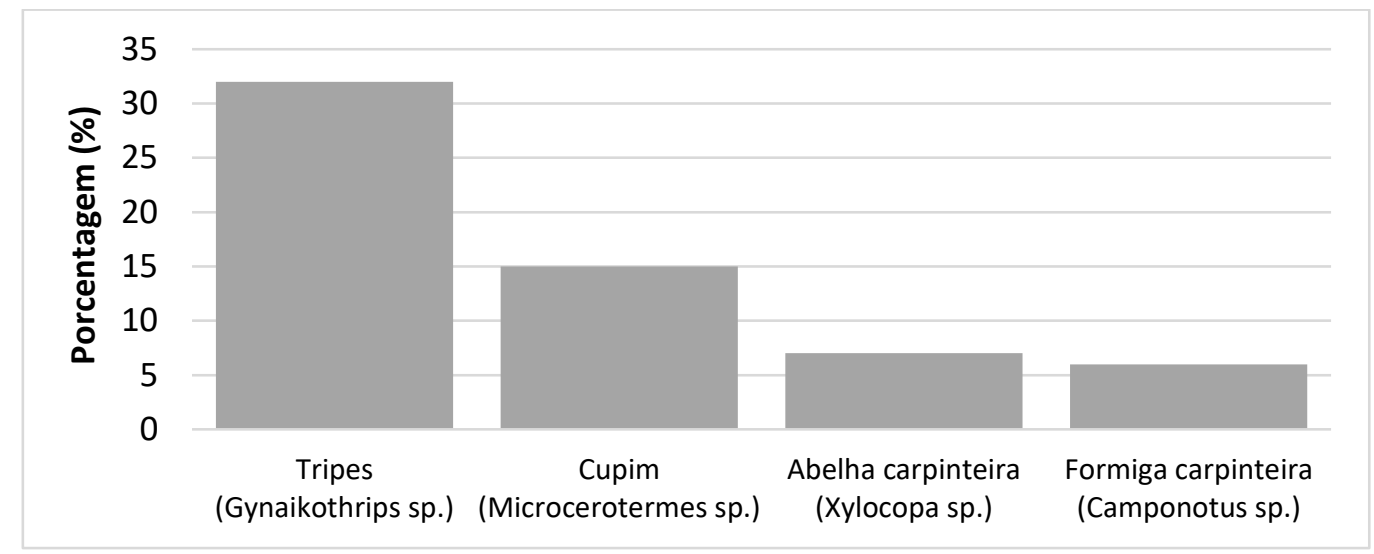

Figura 16. Insetos em árvores de Ficus benjamina

Figure 16. Insects in Ficus benjamina trees

A associação Apriori demonstrou que a poda apresentou maior quantidade de associações com a presença de defeitos do que com a ausência, sendo três defeitos associados à presença de poda, e apenas um defeito com associação negativa, indicando a ausência do mesmo quando a árvore é podada (Tabela 3 ). 
Tabela 3. Associação Apriori entre os defeitos e a poda de Ficus benjamina

Table 3. Apriori association between defects and Ficus benjamina pruning

\begin{tabular}{lccc}
\hline Defeito & Associação & Confiança & Lift \\
\hline Tronco - cupim & Positiva & 1,00 & 1,43 \\
Copa - Brotações epicórmicas & Positiva & 0,97 & 1,38 \\
Tronco - lesão & Positiva & 0,91 & 1,3 \\
Copa - Erva de passarinho & Negativa & 0,99 & 1 \\
\hline
\end{tabular}

A associação entre a poda e as lesões e também entre a poda e a presença de cupins no tronco, pode ser justificada pela injúria causada pelas podas mau executadas, que expõe o lenho da inserção do galho à ação de patógenos e microorganismos decompositores (USDA, 1992; GILMAN 2012).

Assim, os resultados demonstram que a poda de Ficus benjamina em Itanhaém teve maior associação com a ocorrência de defeitos do que com a sua prevenção, comprometendo sua estrutura e fitossanidade e também podendo contribuir com um aumento da probabilidade de risco de queda dessas árvores.

\section{CONCLUSÕES}

A poda das árvores de Ficus benjamina no município de Itanhaém são frequentes, sendo a poda de redução a mais frequente nas árvores, onde é realizada principalmente pela prática de ornamentação.

Alguns defeitos estruturais ocorreram em grande frequência independente da poda, como os galhos secos, rachaduras no tronco e raízes adventícias. Esses defeitos comprometem a utilização da espécie em calçadas, tanto pelos possíveis danos causados ao patrimônio, como também por potencializar o risco de queda destas árvores, podendo atingir pedestres e moradores.

Porém, a poda muitas vezes potencializou o surgimento de defeitos que comprometem a estrutura das árvores, como por exemplo, as brotações epicórmicas na copa, lesões e presença de cupins no tronco.

Assim, ressalta-se que a poda deve ser realizada por profissionais especializados, para que os aspectos estéticos sejam aplicados em conjunto com técnicas de preservação dos aspectos sanitários e estruturais, evitando o surgimento e potencialização do risco de queda. 


\section{AGRADECIMENTOS}

Esta pesquisa foi realizada graças ao fomento da CAPES (coordenação de aperfeiçoamento de Pessoal de Nível superior) através da bolsa de pesquisa de doutorado do primeiro e segundo autores.

\section{REFERÊNCIAS}

ALBERTIN, R. M.; DE ANGELIS, R.; DE ANGELIS NETO, G.; DE ANGELIS, B. L. Diagnóstico quali-quantitativo da arborização viária de Nova Esperança, Paraná, Brasil. Revista da Sociedade Brasileira de Arborização Urbana, Piracicaba, v. 6, n.3, p. 128-148, 2011.

ALVAREZ, C. A.; STAPE, J. L.; SENTELHAS, P. C.; GONÇALVES, J. L. M.; SPAROVEK, G. Köppen's climate classification map for Brazil. Meteorologische Zeitschrift, Stuttgart, v.22, n.6, p.711-728, 2014.

BIONDI, D. Floresta urbana. Curitiba: O Autor, 2015.

BOBROWSKI, R.; BIONDI, D. Distribuição e dinâmica da área de copa na arborização de ruas de Curitiba, Paraná, Brasil, no período de 1984-2010. Revista Árvore, Viçosa, v.36, n.4, p.625$635,2012$.

FERNANDES, T. P.; XIMENES, L. C. Comportamento de Ficus na arborização urbana do bairro Santa Clara, Santarém/Pará. Revista Ibero Americana de Ciências Ambientais, v.11, n.1, p.29-39, 2020.

GILMAN, E. F. An illustrated guide to prunning. Nova lorque: Delmar, 2012, 476 p.

GILMAN, E. F.; GRABOSKY, J. C. Branch Union Morphology Affects Decay Following Pruning. Arboriculture \& Urban Forestry, Atlanta, v. 32, n. 2, 2006.

GUEVARA-ESCOBAR, A.; GONZALEZ-SOSA, E.; VELIZ-CHAVEZ, C.; VENTURA-RAMOS, E.; RAMOS-SALINAS, M. Rainfall interception and distribution patterns of gross precipitation around an isolated Ficus benjamina tree in an urban area. Journal of Hidrology. v. 333, p. 532-541, 2007.

GUIMARAES, M. G.; CARDOSO JUNIOR, R. A. F. Diagnóstico e análise dos conflitos da arborização urbana: estudo de caso do bairro do Grajaú (Rio de Janeiro). Revista Internacional de Ciências, Rio de Janeiro, v. 09, n. 01, p. 92 - 104, 2019.

GUZMAN-MORALES, J.; HERNANDEZ-ALVAREZ, E.; GARCIA-ARREOLA, M. E. Assessment of Atmospheric Metal Pollution in the Urban Area of Mexico City, Using Ficus benjamina as Biomonitor. Bulletin of Environmental Contamination and Toxicology, Amsteradm. v. 86, p. 495-500, 2011.

IMRAN, M.; RASOOL, N.; RIZWAN, K.; ZUBAIR, M.; RIAZ, M.; Zia-UI-Haq, M.; RANA, U. A.; NAFADY, A.; JAAFAR, H. Z. Chemical composition and Biological studies of Ficus benjamina. Chemistry central journal, v.8, n. 12, 2014. 
JIM, C. Y.; CHEN, W. Y. Habitat effect on vegetation ecology and occurrence on urban masonry walls. Urban Forestry \& Urban greening, Amsterdam, v. 9, p. 169-178, 2010.

JIM, C. Y.; ZHANG, H. Defect-disorder and risk assessment of heritage trees in urban Hong Kong. Urban Forestry \& Urban greening, Amsterdam, v. 12, p. 585-596, 2013.

LUNDGREN, W.J.C.; SILVA, L.F.; ALMEIDA, A.Q. Influência das espécies exóticas arbóreas urbanas na área de cobertura da cidade de Serra Talhada - PE. Revista da Sociedade Brasileira de Arborização Urbana, Piracicaba, v.8, n.3, p.96-107, 2013.

LIMA NETO, E.M.; BIOND, D.; ARAKI, H.; BOBROWSKI, R. Fotografias aéreas para mensuração da área de copa das árvores de ruas de Curitiba - PR. Floresta, Curitiba, v. 42, n. 3, p. 577 - 586, 2012.

MARIA, T. R. B. C.; ZAMPRONI, K.; BIONDI, D. Avaliação quali-quantitativa de Ficus benjamina Linn. na arborização viária de Itanhaém - SP. Acta biológica catarinense, Joinville, v. 7, n. 1, p. 82-91, 2020.

MARTELLI, A.; BARBOSA JUNIOR, J. Análise da incidência de supressão arbórea e suas principais causas no perímetro urbano do município de Itapira-SP. Revista da Sociedade Brasileira de Arborização Urbana, Piracicaba, v.5, n.4, p.96-109, 2010.

MCPHERSON, E. G.; XIAO, Q.; VAN DOORN, N. S.; GOEDE, J.; BJORKMAN, J.; HOLLANDER, A.; BONYNTON, R.M.; QUINN, J.F.; THORNE, J.H. The structure, function and value of urban forests in California communities. Urban Forestry \& Urban Greening, Amsterdam, v.28, p. 4353, 2017.

SANTOS, C. T. F.; OLIVEIRA, I. M. M.; FIALHO JUNIOR, L. L.; VERLY, O. M.; ROSA, P. R.; FRANCO, F. M.; CHAVES, A. G. F. Silvicultura Urbana: Levantamento e caracterização da arborização em uma área central na cidade de Cáceres-MT. Revista de Educação, Ciência e Tecnologia do IFRS, Porto Alegre, v.6, n.1, p: 47-64, 2019.

SEITZ, R. Avaliação visual de árvores de risco. Curitiba: FUPEF/SBAU, 2005, 26 p.

SMILEY, E. T.; MATHENY, N.; LILLY, S. Best Management Practices - Tree Risk Assessment, Illinois: International Society of Arboriculture, 2011.

STARR, F.; STARR, K.; LOOPE, L. Ficus benjamina. Pesquisas Geológicas dos Estados Unidos - Divisão de pesquisas biológicas. Disponível em: http://hear.its.hawaii.edu/ Pier/pdf/pohreports/ficus_benjamina.pdf. Acesso em: 31 de janeiro de 2019.

SREETHERAN, M.; ADNAN, M; KHAIRIL AZUAR, A. K. Street Tree Inventory and Tree Risk Assessment of Selected Major Roads in Kuala Lumpur, Malaysia. Arboriculture \& Urban Forestry, Atlanta, v. 37, n. 5, p. 226-235, 2011.

USDA - UNITED STATE DEPARTMENT OF AGRICULTURE. Urban Tree Risk Management: A Community Guide to Program Design and Implementation. Minessota, USDA Forest Service, 1992, 204 p.

VARGAS-GÁRZON, B.; MOLINA-PRIETO, L. F.; Ficus benjamina L. in the cities: high number of individuals, severe damages to infrastructure and expensive economic losses. Revista nodo, v. 7, n. 13, p. 93-101, 2012. 